\title{
Expression of $\gamma \mathrm{H} 2 \mathrm{AX}$ in various gastric pathologies and its association with Helicobacter pylori infection
}

\author{
CHUAN XIE* , LI-YAO XU* ${ }^{*}$ ZHEN YANG, XI-MEI CAO, WEI LI and NONG-HUALU \\ Department of Gastroenterology, The First Affiliated Hospital, Nanchang University, Nanchang, Jiangxi 330006, P.R. China
}

Received May 6, 2013; Accepted November 12, 2013

DOI: $10.3892 / \mathrm{ol} .2013 .1693$

\begin{abstract}
Phosphorylation of $\mathrm{H} 2 \mathrm{AX}$ at Ser $139(\gamma \mathrm{H} 2 \mathrm{AX})$ is a biomarker of DNA double-strand breaks (DSBs). The present study aimed to explore the association between $\gamma \mathrm{H} 2 \mathrm{AX}$ levels and gastric pathology and Helicobacter pylori (H.pylori) infection. Gastric biopsies were obtained from 302 H.pylori-negative and -positive patients, including those with chronic gastritis (CG), intestinal metaplasia (IM), dysplasia (Dys) and gastric cancer (GC). Proteins were extracted from five gastric epithelial cell lines and from 10 specimens of matched GC and adjacent normal tissues. The expression of $\gamma \mathrm{H} 2 \mathrm{AX}$, a biomarker for the detection of DNA DSBs, in gastric tissues was detected by immunohistochemistry and western blotting. The expression of $\gamma \mathrm{H} 2 \mathrm{AX}$ progressively increased in tissues according to pathological stage from CG to Dys, but was slightly decreased in GC. H. pylori infection was associated with increased $\gamma \mathrm{H} 2 \mathrm{AX}$ expression, IM and Dys. Overexpression of $\gamma \mathrm{H} 2 \mathrm{AX}$ in GC was found to correlate with tumor location, gross appearance, differentiation, depth of invasion, TNM stage and lymph node metastasis. The results indicated that DSBs appear to be an early molecular event in gastric carcinogenesis, which may be associated with $H$. pylori infection. Moreover, immunohistochemical staining of $\gamma \mathrm{H} 2 \mathrm{AX}$ was found to correlate with a number of clinicopathological characteristics. The expression of $\gamma \mathrm{H} 2 \mathrm{AX}$ may serve as a valuable biomarker for the diagnosis and progression of $\mathrm{GC}$.
\end{abstract}

\section{Introduction}

Gastric cancer (GC) is the fourth most common malignancy and the second leading cause of cancer mortality worldwide (1). Helicobacter pylori (H. pylori) is a gram-negative bacteria that infects $50 \%$ of the global population. However,

Correspondence to: Professor Nong-Hua Lu, Department of Gastroenterology, The First Affiliated Hospital, Nanchang University, 17 Yongwai Road, Nanchang, Jiangxi 330006, P.R. China E-mail: lunonghua@ncu.edu.cn

*Contributed equally

Key words: Helicobacter pylori, DNA double-strand breaks, $\gamma \mathrm{H} 2 \mathrm{AX}$, gastric carcinogenesis in certain regions and countries of the world, $>80 \%$ of the population is infected with the bacteria. $H$. pylori has been defined by the International Agency for Research of Cancer as a class I carcinogen and is important for the progression from chronic superficial gastritis to chronic atrophic gastritis, intestinal metaplasia (IM), dysplasia (Dys) and finally GC (2).

DNA double-strand breaks (DSBs) are the most serious type of DNA damage and are frequently caused by ionizing radiation (IR), ultraviolet light and specific chemical agents. Recently, H. pylori has also been shown to induce DSBs in gastric epithelial cells in vitro $(3,4)$. Inappropriate repair of DSBs can result in genomic instability, which has been shown to be a key factor in carcinogenesis (5). Phosphorylation of $\mathrm{H} 2 \mathrm{AX}$ at Ser $139(\gamma \mathrm{H} 2 \mathrm{AX})$ is abundant, fast, correlates well with DSBs and renders $\gamma \mathrm{H} 2 \mathrm{AX}$ a sensitive marker for the detection of DSBs (6). The expression of $\gamma \mathrm{H} 2 \mathrm{AX}$ has been shown to correlate with numerous types of malignant tumor and also with prognosis in early operable non-small cell lung cancer, vulvar squamous cell carcinoma and breast cancer (7-9).

There have been a number of studies on $\gamma \mathrm{H} 2 \mathrm{AX}$ expression in GC tissues. Sentani et al (10) showed that nuclear positive staining for GC was significantly higher than that in normal gastric tissues. However, no previous studies have investigated $\gamma \mathrm{H} 2 \mathrm{AX}$ expression in various gastric lesions or its correlation with $H$. pylori infection. Therefore, the aim of the present study was to measure the expression of $\gamma \mathrm{H} 2 \mathrm{AX}$ and determine its correlation with the various stages of gastric carcinogenesis, in the presence or absence of $H$. pylori infection.

\section{Patients and methods}

Patients and sample collection. Gastric tissue samples were collected from patients who had undergone an upper gastroduodenoscopy or gastrectomy at the First Affiliated Hospital of Nanchang University (Nanchang, China) between January 2007 and September 2008. A total of 302 patients ranging in age between 18 and 70 years were enrolled in the current study. The study included 56 cases of chronic gastritis (CG), 53 of IM, 47 of Dys and 146 of GC. None of the patients had been treated with proton pump inhibitors or antibiotics against $H$. pylori, and no GC patients had been treated with prior radio- or chemotherapy. The clinical characteristics of these patients are summarized in Table I. No significant differences were identified in the age or gender distribution among these groups. Clinicopathological characteristics were also obtained from the pathological reports. 
In total, $10 \mathrm{GC}$ tissue samples and adjacent normal tissues were collected from gastrectomy specimens at the First Affiliated Hospital of Nanchang University.

The present study was approved by the Ethics Committee of the First Affiliated Hospital of Nanchang University. All patients provided written informed consent prior to enrollment in the study.

Histological examination. All biopsies or surgical specimens from the patients with gastric disease were obtained from the gastric antrum or lesion locations. The tissues used for histological analysis were fixed in $10 \%$ formaldehyde in $\mathrm{Ca}^{2+}$ and $\mathrm{Mg}^{2+}$-free phosphate-buffered saline (PBS) overnight at $4^{\circ} \mathrm{C}$, prior to paraffin embedding. Paraffin sections, $4 \mu \mathrm{m}$ thick, were sectioned with a microtome and stored at room temperature. Pathological diagnosis and classification were performed according to the criteria of the World Health Organization (11) and the updated Sydney system (12).

Detection of H. pylori infection. Rapid urease test and modified Giemsa staining were used for the detection of $H$. pylori infection. The modified Giemsa staining was performed by two veteran pathologists. Consistency in the positive or negative results of the two tests was required.

Immunohistochemistry. Slices were deparaffinized in dimethylbenzene, rehydrated through 100, 95 and $85 \%$ ethanol and incubated with fresh $3 \% \mathrm{H}_{2} \mathrm{O}_{2}$ for $10 \mathrm{~min}$ to quench endogenous peroxidase activity. Microwave heating was used to expose antigens for detection. The primary antibody used for immunohistochemistry was rabbit monoclonal anti-human $\gamma$ H2AX (ab81299; 1:400; Abcam, Cambridge, UK). Slices were incubated at $4^{\circ} \mathrm{C}$ overnight and then washed with PBS three times. The secondary antibody (PV-6000; Zhongshan Golden Bridge Biotechnology Co., Ltd., Beijing, China) was incubated at $37^{\circ} \mathrm{C}$ for $30 \mathrm{~min}$ prior to reaction with 3,3-diaminobenzidine (Zhongshan Golden Bridge Biotechnology Co. Ltd.). Subsequently, slices were counterstained with hematoxylin and mounted with coverslips. Negative controls consisted of PBS without primary antibody (13).

Review and scoring. The stained slices were reviewed and scored by two experienced pathologists. The concordance rates were generally high and results with any grading discrepancies were re-reviewed and discussed to determine a final score. Epithelial cells stained yellow or brown in the nuclei were defined as positive. Five fields for each slice were randomly selected, reviewed and scored (magnification, x 200). In each field, 100 immunoreactive cells were assessed and quantified as the percentage of total cells and then averaged from the five fields to calculate the percentage of immunostaining, i.e. $0, \leq 5.0 \% ; 1,5.1-25.0 \% ; 2,25.1-50.0 \%$; 3, 50.1-75.0\%; and 4, $>75.0 \%$. Moreover, the staining intensity was also semi-quantitatively assessed as follows: 0 , no staining; 1 , weak staining; 2 , moderate staining; and 3, strong staining. The integrals of the 'area $\mathrm{x}$ intensity' were calculated based on the following overall scores of the expression levels of the proteins in the sections: negative (-), $0-2$; weak positive $(+), 3-5$; moderate positive $(++), 6-8$; and strong positive (+++), 9-12 (Table I) (13).
Cell lines and culture. Five gastric mucosal cell lines were used in the present study, including GES-1 (immortalized gastric epithelial mucosa cell line, established by the Beijing Institute for Cancer Research, Beijing, China) and human gastric cancer SGC7901, MKN28, MKN45 and AGS cell lines (a gift from the Xijing Hospital of Digestive Disease, Xi'an, China). Cell lines were cultured at $37^{\circ} \mathrm{C}$ in an atmosphere of $5 \% \mathrm{CO}_{2}$ in DMEM with $10 \%$ fetal bovine serum, 100 units penicillin and $100 \mu \mathrm{g} / \mathrm{ml}$ streptomycin (Gibco-BRL, Carlsbad, CA, USA) (14).

Western blotting. Tissues and cells were lysed in a buffer containing $0.5 \%$ Lubrol-PX, $50 \mathrm{mM} \mathrm{KCl}, 2 \mathrm{mM} \mathrm{CaCl}_{2}$, $20 \%$ glycerol, $5 \mathrm{mM}$ Tris- $\mathrm{HCl}(\mathrm{pH} 7.4), 0.1 \%$ protease and $1 \%$ phosphatase inhibitors (Sigma-Aldrich, St. Louis, MO, USA). Following the addition of sodium dodecyl sulfate-polyacrylamide gel electrophoresis (SDS-PAGE) sample buffer, proteins were run on an SDS-PAGE gel and transferred to nitrocellulose membranes (Whatman GmbH, Dassel, Germany). The membranes were immunoblotted with antibodies against $\gamma \mathrm{H} 2 \mathrm{AX}$ (ab81299; 1:1,000; Abcam) and actin (1:1,000; Zhongshan Golden Bridge Biotechnology, Co., Ltd.). The reactions were subjected to incubation with an enhanced chemiluminescence detection system (Pierce Biotechnology, Inc., Rockford, IL, USA) and then exposed to X-ray film for visualizing the positive bands.

Statistical analysis. SPSS 17.0 (SPSS Inc., Chicago, IL, USA) was used to perform the statistical analysis. Data are expressed as the mean \pm standard deviation or percentage. The $\chi^{2}$ test was used to evaluate differences in categorical variables. The Kruskal-Wallis one-way analysis of variance and Mann-Whitney U tests were used to determine differences in numerical variables between various groups. $\mathrm{P}<0.05$ was considered to indicate a statistically significant difference.

\section{Results}

Differential expression of $\gamma H 2$ AX in various gastric lesions and its association with $H$. pylori infection. Immunohistochemical analysis showed that $\gamma \mathrm{H} 2 \mathrm{AX}$ was primarily found in the nuclei of epithelial cells. Semi-quantitative results of the expression of $\gamma \mathrm{H} 2 \mathrm{AX}$ are shown in Table I. The results showed that the expression ratio of $\gamma \mathrm{H} 2 \mathrm{AX}$ was $48.2 \%$ in the $\mathrm{CG}$ group, $73.5 \%$ in the IM group, $95.7 \%$ in the Dys group and $89.7 \%$ in the GC group. Consistent with the observations of Correa et al (2), the expression levels of $\gamma \mathrm{H} 2 \mathrm{AX}$ in the current study were significantly increased as pathological stages progressed from $\mathrm{CG}$ to Dys $(\mathrm{P}<0.001)$. However, expression levels were decreased in GC ( $\mathrm{P}=0.011)$ (Fig. 1 and Table I). The expression of $\gamma \mathrm{H} 2 \mathrm{AX}$ was also measured by western blotting in GC and adjacent normal tissues. The results showed high $\gamma \mathrm{H} 2 \mathrm{AX}$ expression in GC tissues compared with adjacent normal tissues $(\mathrm{P}<0.001)$ (Fig. 2), which is consistent with the immunohistochemical results.

Moreover, in patients with IM and Dys, the expression of $\gamma \mathrm{H} 2 \mathrm{AX}$ was significantly higher in the presence of $H$. pylori infection (96.5 and 100\%, respectively) compared with those without the infection ( 45.8 and $90.4 \%$, respectively) $(\mathrm{P}=0.001$ and $\mathrm{P}=0.008$ ) (Table II). However, no significant differences were detected in the CG or GC groups. 
Table I. Expression of $\gamma \mathrm{H} 2 \mathrm{AX}$ in patients with various histological observations.

Overall score of $\gamma \mathrm{H} 2 \mathrm{AX}$ expression

\begin{tabular}{lrcrrrrrrr}
\cline { 5 - 8 } Group & \multicolumn{1}{c}{$\mathrm{n}$} & Mean age (SD), years & Gender, M/F &,$- \mathrm{n}$ &,$+ \mathrm{n}$ &,$++ \mathrm{n}$ &,$+++ \mathrm{n}$ & $\%^{\mathrm{a}}$ & \multirow{2}{*}{ P-value } \\
\hline 1 CG & 56 & $53.6(10.7)$ & $30 / 26$ & 29 & 27 & 0 & 0 & 48.2 & \\
2 IM & 53 & $54.3(9.6)$ & $29 / 24$ & 14 & 26 & 12 & 1 & 73.5 & $<0.001^{\mathrm{b}}$ \\
3 Dys & 47 & $55.1(10.3)$ & $26 / 21$ & 2 & 9 & 27 & 9 & 95.7 & $<0.001^{\mathrm{b}, \mathrm{c}}$ \\
4 GC & 146 & $56.8(14.1)$ & $96 / 50$ & 15 & 57 & 50 & 24 & 89.7 & $<0.001^{\mathrm{b}} ; 0.011^{\mathrm{d}}$ \\
\hline
\end{tabular}

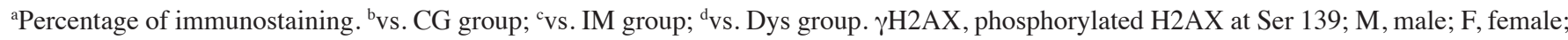
CG, chronic gastritis; IM, intestinal metaplasia; Dys, dysplasia; GC, gastric cancer.
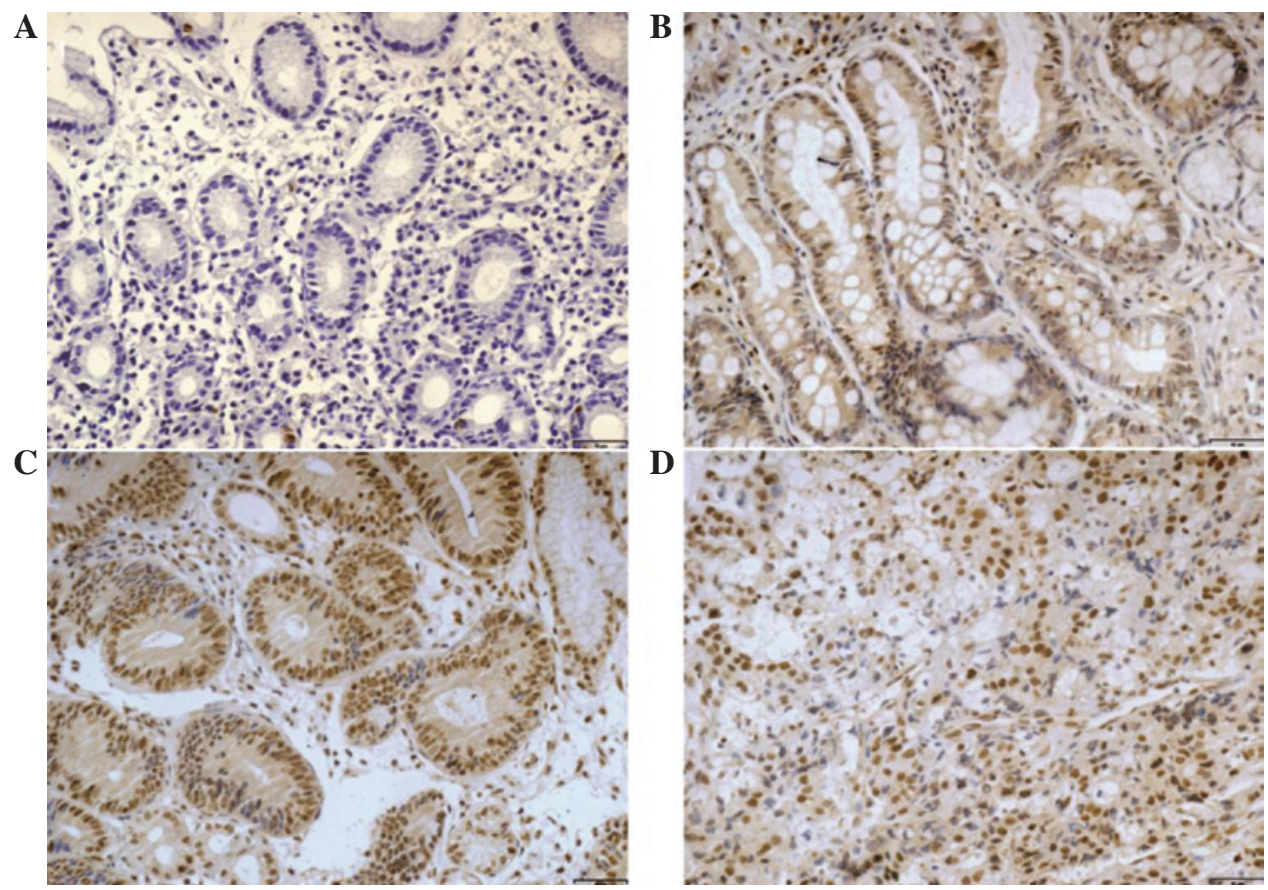

Figure 1. Immunohistochemical staining of $\gamma \mathrm{H} 2 \mathrm{AX}$ protein in (A) chronic gastritis, (B) intestinal metaplasia, (C) dysplasia and (D) gastric carcinoma tissues (magnification, x200; scale bar, $40 \mu \mathrm{m}$ ). $\gamma \mathrm{H} 2 \mathrm{AX}$, phosphorylated $\mathrm{H} 2 \mathrm{AX}$ at Ser 139.

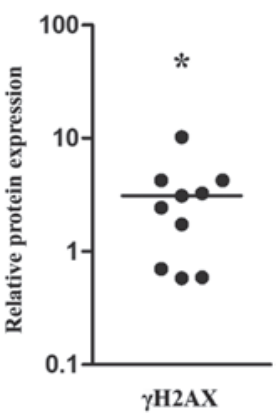

Figure 2. Relative $\gamma \mathrm{H} 2 \mathrm{AX}$ protein expression levels in gastric carcinoma compared with adjacent non-tumorous mucosa. Immunoblots of $\gamma \mathrm{H} 2 \mathrm{AX}$ were scanned and the relative protein expression level of tumor samples were compared with their adjacent non-cancerous counterparts and expressed as a percentage of $\beta$-actin. " $\mathrm{P}<0.001 . \gamma \mathrm{H} 2 \mathrm{AX}$, phosphorylated $\mathrm{H} 2 \mathrm{AX}$ at Ser 139.

The association of $\gamma \mathrm{H} 2 \mathrm{AX}$ expression with clinicopathological parameters was analyzed in $146 \mathrm{GC}$ patients (Table III). The gastric body and cardia cancers showed a higher $\gamma \mathrm{H} 2 \mathrm{AX}$

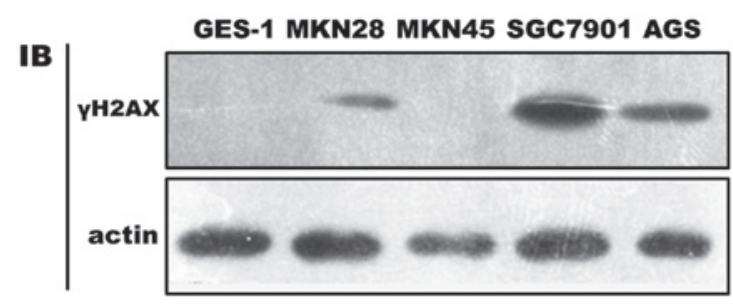

Figure 3. Expression of $\gamma \mathrm{H} 2 \mathrm{AX}$ in non-cancerous and cancerous gastric cell lines measured by western blotting. Cell lines were grown for two days and then subjected to total cellular protein isolation. $\gamma \mathrm{H} 2 \mathrm{AX}$, phosphorylated $\mathrm{H} 2 \mathrm{AX}$ at Ser 139 .

expression (97.2\%) than gastric antrum cancers $(82.4 \%)$ $(\mathrm{P}<0.001)$. In addition, the expression of $\gamma \mathrm{H} 2 \mathrm{AX}$ in Borrmann III and IV type GC (90.5\%) was significantly higher than Borrmann I and II type GC (88.9\%) (P=0.002). $\gamma \mathrm{H} 2 \mathrm{AX}$ expression in poorly- and undifferentiated GC $(93.8 \%)$ was significantly higher compared with that in well- and moderately 
Table II. Expression of $\gamma \mathrm{H} 2 \mathrm{AX}$ in patients with various histological observations, in relation to H. pylori infection.

\begin{tabular}{|c|c|c|c|c|c|c|c|c|c|c|}
\hline \multirow[b]{2}{*}{ Group } & \multirow[b]{2}{*}{ H.pylori } & \multirow[b]{2}{*}{$\mathrm{n}$} & \multirow[b]{2}{*}{ Mean age (SD), years } & \multirow[b]{2}{*}{ Gender, M/F } & \multicolumn{6}{|c|}{ Overall score of $\gamma \mathrm{H} 2 \mathrm{AX}$ expression } \\
\hline & & & & &,$- \mathrm{n}$ &,$+ \mathrm{n}$ &,$++ \mathrm{n}$ &,$+++ \mathrm{n}$ & $\%^{a}$ & P-value \\
\hline \multirow[t]{2}{*}{$\mathrm{CG}$} & + & 26 & $54.1(11.7)$ & $14 / 12$ & 7 & 19 & 0 & 0 & 73.1 & 0.362 \\
\hline & - & 30 & $53.2(9.1)$ & $16 / 14$ & 22 & 8 & 0 & 0 & 26.7 & \\
\hline \multirow[t]{2}{*}{ IM } & + & 29 & $54.8(8.8)$ & $14 / 15$ & 1 & 19 & 8 & 1 & 96.5 & 0.001 \\
\hline & - & 24 & $53.7(10.3)$ & $15 / 9$ & 13 & 7 & 4 & 0 & 45.8 & \\
\hline \multirow[t]{2}{*}{ Dys } & + & 26 & $54.3(12.2)$ & $13 / 13$ & 0 & 2 & 17 & 7 & 100.0 & 0.008 \\
\hline & - & 21 & $56.1(9.5)$ & $13 / 8$ & 2 & 7 & 10 & 2 & 90.4 & \\
\hline \multirow[t]{2}{*}{$\mathrm{GC}$} & + & 61 & $58.3(16.3)$ & $39 / 22$ & 6 & 25 & 20 & 10 & 90.2 & 0.865 \\
\hline & - & 85 & $50.8(13.9)$ & $57 / 28$ & 9 & 32 & 30 & 14 & 89.4 & \\
\hline
\end{tabular}

${ }^{a}$ Percentage of immunostaining. $\gamma \mathrm{H} 2 \mathrm{AX}$, phosphorylated H2AX at Ser 139; H. pylori: Helicobacter pylori; M, male; F, female; CG, chronic gastritis; IM, intestinal metaplasia; Dys, dysplasia; GC, gastric cancer.

Table III. Clinicopathological association of $\gamma \mathrm{H} 2 \mathrm{AX}$ expression in patients with GC.

\begin{tabular}{|c|c|c|c|c|c|c|c|}
\hline \multirow[b]{2}{*}{ Characteristics } & \multirow[b]{2}{*}{$\mathrm{n}$} & \multicolumn{6}{|c|}{ Overall score of $\gamma \mathrm{H} 2 \mathrm{AX}$ expression } \\
\hline & &,$- \mathrm{n}$ &,$+ \mathrm{n}$ &,$++ \mathrm{n}$ &,$+++ \mathrm{n}$ & $\mathrm{PR}, \%$ & P-value \\
\hline \multicolumn{8}{|l|}{ Gender } \\
\hline Male & 96 & 8 & 39 & 35 & 14 & 91.7 & 0.923 \\
\hline Female & 50 & 7 & 18 & 15 & 10 & 86.0 & \\
\hline \multicolumn{8}{|l|}{ Age, years } \\
\hline$\geq 55$ & 86 & 7 & 36 & 28 & 15 & 91.8 & 0.780 \\
\hline$<55$ & 60 & 8 & 21 & 22 & 9 & 86.7 & \\
\hline \multicolumn{8}{|l|}{ Location } \\
\hline Antrum & 74 & 13 & 31 & 25 & 5 & 82.4 & $<0.001$ \\
\hline Body and cardia & 72 & 2 & 26 & 25 & 19 & 97.2 & \\
\hline \multicolumn{8}{|l|}{ Gross type (Borrmann) } \\
\hline I and II & 72 & 8 & 37 & 21 & 6 & 88.9 & 0.002 \\
\hline III and IV & 74 & 7 & 20 & 29 & 18 & 90.5 & \\
\hline \multicolumn{8}{|l|}{ Differentiation } \\
\hline Well and moderately & 81 & 11 & 40 & 21 & 9 & 74.1 & \\
\hline Poorly and undifferentiated & 65 & 4 & 17 & 29 & 15 & 93.8 & $<0.001$ \\
\hline \multicolumn{8}{|l|}{ Invasive depth } \\
\hline Above submucosa & 27 & 4 & 18 & 3 & 2 & 85.1 & \\
\hline Muscularis propria & 8 & 2 & 0 & 3 & 3 & 75.0 & $0.080^{\mathrm{a}}$ \\
\hline Below subserosa & 111 & 9 & 39 & 44 & 19 & 91.9 & $0.002^{\mathrm{a}} ; 0.373^{\mathrm{b}}$ \\
\hline \multicolumn{8}{|l|}{ TNM } \\
\hline I and II & 59 & 8 & 35 & 12 & 3 & 86.4 & $<0.001$ \\
\hline III and IV & 87 & 7 & 22 & 38 & 20 & 91.9 & \\
\hline \multicolumn{8}{|l|}{ Lymph node metastasis } \\
\hline With & 113 & 10 & 37 & 45 & 21 & 91.2 & 0.002 \\
\hline Without & 33 & 5 & 20 & 5 & 3 & 84.8 & \\
\hline
\end{tabular}

${ }^{\mathrm{a}}$ VS. above submucosa; ${ }^{\mathrm{b}} \mathrm{vs}$. muscularis propria. $\gamma \mathrm{H} 2 \mathrm{AX}$, phosphorylated H2AX at Ser 139; GC, gastric cancer; PR, positive rate.

differentiated GC $(74.1 \%)(\mathrm{P}<0.001)$. In cancer tissues located in the submucosa, the $\gamma \mathrm{H} 2 \mathrm{AX}$ expression $(85.1 \%)$ was significantly lower than that in cancer tissues that had reached the subserosal level $(91.9 \%)(\mathrm{P}=0.002)$. Furthermore, $\gamma \mathrm{H} 2 \mathrm{AX}$ was expressed more frequently in TNM III and IV stage patients (91.9\%) than in TNM I and II stage patients $(86.4 \%)(\mathrm{P}<0.001)$, and there was 
higher $\gamma \mathrm{H} 2 \mathrm{AX}$ expression in the patients with lymph node metastasis $(91.2 \%)$ than in the patients without $(84.8 \%)(\mathrm{P}=0.002)$.

Differential expression of $\gamma H 2 A X$ in various gastric epithelial cell lines. Expression of $\gamma \mathrm{H} 2 \mathrm{AX}$ was higher in GC cell lines (i.e., SGC-7901, MKN-28 and AGS, with the exception of MKN-45) compared with the non-cancerous cell line GES-1 (Fig. 3).

\section{Discussion}

DSBs are important threats to genome integrity causing chromosomal aberrations, which are remarkable characteristics of malignant tumors (15). While the response to DNA damage acts as an anticancer barrier in early human tumorigenesis, $\gamma \mathrm{H} 2 \mathrm{AX}$ has been reported to be highly overexpressed in precancerous lesions of the urinary bladder, breast, lung and colon cancer (16). In the current study, the expression of $\gamma \mathrm{H} 2 \mathrm{AX}$ was shown to progressively increase in accordance with the pathological progression from CG to Dys. $\gamma \mathrm{H} 2 \mathrm{AX}$ expression in GC was also higher than that in $\mathrm{CG}$, but was slightly decreased in Dys. The reason for lower $\gamma \mathrm{H} 2 \mathrm{AX}$ expression in GC compared with Dys remains unclear; however, restoration of genomic instability during tumor progression may explain this observation $(17,18)$. The western blotting results of the cancer and adjacent normal tissues were confirmed by cell line experiments. All results showed that the response to DNA damage was activated in gastric precancerous lesions.

Recently, Toller et al have shown that $H$. pylori triggers DSBs in gastric epithelial cells in cell culture, primarily mediated by $H$. pylori blood group antigen-binding adhesion (3). In addition, Jang et al have shown that $H$. pylori-induced DSBs may be inhibited by lycopene (4). The two investigations were based on AGS coculture with H.pylori in cell culture, a model system which is different from the clinical situation. The results of the current study were based on human samples and showed that high expression of $\gamma \mathrm{H} 2 \mathrm{AX}$ in IM and Dys patients appeared to correlate with $H$. pylori infection, which implied that $H$. pylori not only induces DSBs in cell culture, but may also be involved in an early molecular event in gastric tumorigenesis. However, whether the DNA damage response pathways are impaired requires further study.

The observations of the current study have shown that the overexpression of $\gamma \mathrm{H} 2 \mathrm{AX}$ in GC correlates with a number of clinicopathological characteristics, including tumor location, tumor gross type, differentiation, tumor invasion depth, TNM stage and lymph node metastasis. All these correlations implied that, as the degree of malignancy increased, the genomic instability was also significantly increased. These results confirm previous observations by Sentani et al (10), in which the expression of the $\gamma \mathrm{H} 2 \mathrm{AX}$ protein in GC was significantly higher in non-neoplastic gastric mucosa and its high expression was also found to correlate with stage II-IV cases. Exposure to IR was an important factor in the study.

In conclusion, DSBs appear to be an early molecular event in gastric carcinogenesis, which is associated with $H$. pylori infection and a number of clinical characteristics. Although the exact mechanism by which DSBs are induced by $H$. pylori infection remains unclear, the expression of $\gamma \mathrm{H} 2 \mathrm{AX}$ may serve as a valuable biomarker for the diagnosis and progression of GC.

\section{Acknowledgements}

The current study was supported in part by grants from the National Natural Science Foundation of China (no. 81270479) and the Graduate Innovative Foundation of Jiangxi Province, China (no. YC2013-B004).

\section{References}

1. Ferlay J, Shin HR, Bray F, Forman D, Mathers C and Parkin DM: Estimates of worldwide burden of cancer in 2008 : GLOBOCAN 2008. Int J Cancer 127: 2893-2917, 2010.

2. Correa P: Human gastric carcinogenesis: a multistep and multifactorial process - First American Cancer Society Award Lecture on Cancer Epidemiology and Prevention. Cancer Res 52: 6735-6740, 1992.

3. Toller IM, Neelsen KJ, Steger M, Hartung ML, Hottiger MO, Stucki M, et al: Carcinogenic bacterial pathogen Helicobacter pylori triggers DNA double-strand breaks and a DNA damage response in its host cells. Proc Natl Acad Sci USA 108: 14944-14949, 2011.

4. Jang SH, Lim JW, Morio T and Kim H: Lycopene inhibits Helicobacter pylori-induced ATM/ATR-dependent DNA damage response in gastric epithelial AGS cells. Free Radic Biol Med 52: 607-615, 2012.

5. Smith J, Tho LM, Xu N and Gillespie DA: The ATM-Chk2 and ATR-Chk1 pathways in DNA damage signaling and cancer. Adv Cancer Res 108: 73-112, 2010.

6. Sharma A, Singh K and Almasan A: Histone H2AX phosphorylation: a marker for DNA damage. Methods Mol Biol 920: 613-626, 2012.

7. Matthaios D, Foukas PG, Kefala M, Hountis P, Trypsianis G, Panayiotides IG, et al: $\gamma-\mathrm{H} 2 \mathrm{AX}$ expression detected by immunohistochemistry correlates with prognosis in early operable non-small cell lung cancer. Onco Targets Ther 5: 309-314, 2012.

8. Brustmann H, Hinterholzer $\mathrm{S}$ and Brunner $\mathrm{A}$ : immunohistochemical expression of survivin and $\gamma-\mathrm{H} 2 \mathrm{AX}$ in vulvar intraepithelial neoplasia and low-stage squamous cell carcinoma. Int J Gynecol Pathol 30: 583-590, 2011.

9. Nagelkerke A, van Kuijk SJ, Sweep FC, Nagtegaal ID, Hoogerbrugge N, Martens JW, et al: Constitutive expression of $\gamma-\mathrm{H} 2 \mathrm{AX}$ has prognostic relevance in triple negative breast cancer. Radiother Oncol 101: 39-45, 2011.

10. Sentani K, Oue N, Sakamoto N, Nishisaka T, Fukuhara T, Matsuura $\mathrm{H}$ and Yasui W: Positive immunohistochemical staining of gammaH2AX is associated with tumor progression in gastric cancers from radiation-exposed patients. Oncol Rep 20: 1131-1136, 2008.

11. Hamilton SR and Aaltonen LA (eds): Pathology and genetics of tumours of the digestive system. In: World Health Organization Classification of Tumours. IARC Press, Lyon, 2000.

12. Dixon MF, Genta RM, Yardley JH and Correa P: Classification and grading of gastritis. The updated Sydney System. International Workshop on the Histopathology of Gastritis, Houston 1994. Am J Surg Pathol 20: 1161-1181, 1996.

13. Yang Z, Shu X, Chen L, Chen J, Xie Y and Lu NH: Expression of p53-MDM2 feedback loop related proteins in different gastric pathologies in relation to Helicobacter pylori infection: implications in gastric carcinogenesis. Clin Res Hepatol Gastroenterol 36: 235-243, 2012.

14. Yang Z, Yuan XG, Chen J, Luo SW, Luo ZJ and Lu NH: Reduced expression of PTEN and increased PTEN phosphorylation at residue Ser380 in gastric cancer tissues: a novel mechanism of PTEN inactivation. Clin Res Hepatol Gastroenterol 37: 72-79, 2013.

15. van Gent DC, Hoeijmakers JH and Kanaar R: Chromosomal stability and the DNA double-stranded break connection. Nat Rev Genet 2: 196-206, 2001.

16. Bartkova J, Horejsí Z, Koed K, Krämer A, Tort F, Zieger K, et al: DNA damage response as a candidate anti-cancer barrier in early human tumorigenesis. Nature 434: 864-870, 2005.

17. Martin RW, Orelli BJ, Yamazoe M, Minn AJ, Takeda S and Bishop DK: RAD51 up-regulation bypasses BRCA1 function and is a common feature of BRCA1-deficient breast tumors. Cancer Res 67: 9658-9665, 2007.

18. Martin RW, Connell PP and Bishop DK: The Yin and Yang of treating BRCA-deficient tumors. Cell 132: 919-920, 2008. 